\title{
The Indirect Effect of Parental Intolerance of Uncertainty on Perinatal Mental Health via Mindfulness During COVID-19
}

\author{
Marissa D. Sbrilli ${ }^{1}\left[\right.$ C Katherine Haigler ${ }^{1} \mathbb{D} \cdot$ Heidemarie K. Laurent $^{1} \mathbb{C}$ \\ Accepted: 17 May 2021 / Published online: 2 June 2021 \\ (c) The Author(s), under exclusive licence to Springer Science+Business Media, LLC, part of Springer Nature 2021
}

\begin{abstract}
Objectives The COVID-19 pandemic is associated with mental health difficulties, especially during pregnancy and early postpartum. Intolerance of uncertainty (IU) and reduced capacity for mindfulness - a protective factor for child-bearers-may be particularly relevant factors driving mental health problems given the unpredictable nature of the pandemic. The current study aims to shed light on modifiable paths to perinatal psychological distress by testing whether there is an indirect effect of IU on psychological symptoms through a perceived reduction in mindfulness during the pandemic.

Methods Pregnant individuals $(67 \%, n=133)$ and new mothers within 6 months postpartum $(33 \%, n=66)$ participated in a cross-sectional online survey assessing IU, current and retrospective pre-pandemic mindfulness (FFMQ), and psychological symptoms (anxiety, depression, somatization; BSI). Perceived change in mindfulness was captured by including retrospective mindfulness as a covariate in the PROCESS macro used for analyses.

Results Tests of the direct association between mindfulness, IU, and psychological symptoms showed significant effects of IU $(b=0.46, S E=0.064 ; p<.001)$ and perceived decrease in mindfulness during the pandemic $(b=-0.72, S E=0.08$, $p<.001)$ on psychological symptoms $\left(R^{2}=.21-.34 ; F[2,197]=51.13-52.81, p<.001\right)$. The indirect effect of IU on symptoms via perceived decrease in mindfulness during the pandemic $(b=0.13, S E=0.043,95 \% \mathrm{CI}[.060, .226])$ was significant $\left(R^{2}=.41, F[3,195]=45.08, p<.001\right)$.

Conclusions Results suggest that mothers who are less able to tolerate uncertainty experience more psychological symptoms, in part due to perceived reduction in mindfulness during the pandemic. Future research should examine whether IU is a screening risk marker and target for mindfulness-based interventions to improve maternal well-being and family outcomes.
\end{abstract}

Keywords COVID-19 $\cdot$ Mindfulness $\cdot$ Intolerance of uncertainty $\cdot$ Psychological symptoms $\cdot$ Mediation $\cdot$ Perinatal

Pregnancy and early postpartum are life-changing periods that can bring joy and excitement but also increased uncertainty (Sorenson, 1990), stress, and vulnerability to emotional problems (Fairbrother et al., 2015; Miller et al., 2006). Child-bearers' mental ill-health in the pre- and postpartum period negatively impacts their experience of early motherhood (Beck, 1999), increases the risk for long-term mental health issues (Letourneau et al., 2010), and can negatively impact interpersonal relationships, including with intimate partners/coparents (O'Hara, 1995). Children's trajectories of social-emotional development are profoundly shaped by

Marissa D. Sbrilli

sbrilli2@illinois.edu

1 Department of Psychology, University of Illinois at UrbanaChampaign, Psychology Building, 603 E Daniel St,

Champaign, IL 61820, USA their parents' psychological distress (i.e., depression, anxiety) across gestation and infancy (e.g., Madigan et al., 2018; Mughal et al., 2019), further underlining the importance of identifying child-bearers at risk for perinatal distress and ways to ameliorate it. The COVID-19 pandemic has brought on and/or exacerbated mental health difficulties for many (Cullen et al., 2020; Tull et al., 2020), especially for pregnant individuals and parents in early postpartum (American Psychological Association, 2020; Ceulemans et al., 2020; Chen et al., 2021; Lebel et al., 2020; López-Morales et al., 2021), with depression rates up to $40 \%$ from $15 \%$ pre-pandemic and anxiety rates increased to $72 \%$ from $29 \%$ pre-pandemic in a perinatal sample (Davenport et al., 2020). Given that psychological symptoms, that is, depression, anxiety, and associated physical symptoms, in the pre- and postpartum period, are common (Fairbrother et al., 2015; Meltzer-Brody et al., 2018) and associated with adverse maternal and infant 
outcomes (Brand \& Brennan, 2009; Howard et al., 2014; Kingston et al., 2012; O'Connor et al., 2002), the psychological impact of COVID-19 on child-bearers requires attention (Ceulemans et al., 2020; Chen et al., 2021). There is a need to illuminate processes that can support parents giving birth in these conditions to ensure their well-being and the future well-being of the next generation.

Recent work suggests that the effects of COVID-19 concerns on psychological symptoms in the general population may be mediated by reduced mindfulness (Belen, 2021). Maternal mindfulness-nonjudgmental and purposeful attention to present-moment experience (Kabat-Zinn, 2003) - has been shown to protect against perinatal anxiety and depression (Hicks et al., 2018), to increase parental relationship satisfaction (Gambrel \& Piercy, 2015), and to cultivate sensitive, responsive caregiving in new mothers (Baumrind, 1989; Duncan et al., 2009; Shaddix, 2014; Siegel \& Hartzell, 2003). Parents who are able to be aware, accepting, and responsive to their baby's needs either through an inherent capacity for or a cultivated practice of mindfulness will foster higher-quality parent-child relationships and be better able to avoid automatic patterns of maladaptive parenting behavior (Duncan et al., 2009; Fernandes et al., 2021), thus promoting secure attachment relationships (Siegel \& Hartzell, 2003). In turn, infants of more mindful mothers show benefits in social-emotional development (Braeken et al., 2017; Van den Heuvel, Donkers, et al., 2015; Van den Heuvel, Johannes, et al., 2015), neurocognitive functioning (Van den Heuvel, Donkers, et al., 2015; Van den Heuvel, Johannes, et al., 2015), and neuroendocrine stress regulation (Laurent et al., 2017). Given these cascading effects on family well-being, it is critical to determine which child-bearers are likely to have limited capacity to be present in the face of challenges.

COVID-19 is a paragon of uncertainty that presents expectant/new parents with a multitude of stressors with an unknown end point (e.g., COVID-19 exposure, financial and material hardship, concerns regarding prenatal/postpartum care, relationship strain, and social isolation (Center for Translational Neuroscience, 2020; Ellington et al., 2020; Lebel et al., 2020), while limiting available coping strategies such as social and mental health support. The changes and uncertainties due to the pandemic are putative causes for increased perinatal psychological symptoms for those previously not at risk and even greater increased risk for childbearers already struggling with psychological symptoms, including depression and anxiety (Brooks et al., 2020; Chen et al., 2021). These challenging conditions have resulted in what has been characterized as a mental health crisis with an uncertain end, especially for pregnant people and those who have recently given birth (Grose, 2020).

To address this crisis, a key research priority is examining psychological factors that may influence levels of distress to inform mechanistically driven interventions (Holmes et al., 2020). One such factor is intolerance of uncertainty (IU), defined as fear of the unknown (Carleton, 2012), which is associated with negative reactions to uncertain situations (Dugas et al., 2001). IU is strongly implicated in the etiology of generalized anxiety disorder (GAD; Dugas et al., 1998), but more recently has been included in transdiagnostic models as a central risk and maintenance factor across mental health concerns and an important transdiagnostic intervention target (Boswell et al., 2013; Carleton, 2016; Einstein, 2014; McEvoy \& Mahoney, 2012) in COVID-19 (Freeston et al., 2020).

IU has been shown to predict mental health difficulties (e.g., Paulus et al., 2015; Yook et al., 2010), and there is evidence that this relationship is partially mediated via contemporaneous dispositional mindfulness in a female student sample (Nekić \& Mamić, 2019). Specifically in COVID-19, IU has similarly shown indirect effects on distress through avoidant, maladaptive coping (e.g., self-distraction; Rettie $\&$ Daniels, 2020). During the perinatal period, IU may be a particularly salient familial risk factor as evidence suggests that high IU in pregnancy is associated with pregnancyrelated anxiety (Treleaven, 2020), predicts increased psychological symptoms postpartum (Furtado et al., 2019), and is implicated in parent-infant transmission of mental illness as a cognitive bias learned nonverbally through social referencing (Aktar et al., 2017).

While the relationship between IU and mental health concerns is well established, the mechanisms underlying this association warrant further study; elucidating these potentially modifiable mechanisms can inform which preventive intervention strategies are well suited to employ in a pandemic (Schimmenti et al., 2020). IU is highly associated with worry and rumination, which function as mediators in IU's relationships with symptoms of anxiety and depression, respectively (Yook et al., 2010). Other research suggests that rumination acts as both a moderator and mediator between IU and depression and anxiety symptoms (Liao \& Wei, 2011). Meta-analyses suggest that repetitive negative thinking (worry and rumination) may be a shared mechanism underlying the relationship between IU and anxiety and depression (Gentes \& Ruscio, 2011; McEvoy et al., 2019).

IU is further associated with a failure to employ effective emotion regulation strategies, negative thoughts and emotions about problems, and a perceived inability to cope effectively with aversive responses to uncertainty (Buhr \& Dugas, 2002; Ouellet et al., 2019). Models of IU suggest that one's ability to endure distress resulting from ambiguous situations will likely impact responding, including the use of adaptive (e.g., acceptance; Schimmenti et al., 2020) or maladaptive (e.g., avoidance or denial; Zacher \& Rudolph, 2021) coping strategies in an uncertain situation (Einstein, 2014). In undergraduate samples, IU has been shown to relate to both lower mindfulness and higher psychological symptoms, in particular anxiety 
symptoms such as worry (Kraemer et al., 2016; Papenfuss et al., 2021). This suggests that the ability to tolerate perceived uncertainty may work through the open and nonjudgmental stance of mindfulness to interrupt the repetitive negative thought and maladaptive coping strategies that maintain psychological distress (Deyo et al., 2009; Lotan et al., 2013; Papenfuss et al., 2021; Yook et al., 2010). Thus, IU may play a key role in parents' risk for diminished mindfulness and resultant mental health difficulties in the uniquely uncertain context of the current pandemic.

Identification of factors involved in the development and maintenance of psychological symptoms, including anxiety and mood symptoms, can guide the use of screening measures for early risk detection and selection of interventions well suited to target such factors. As suggested by previous research, IU may serve as a key indicator of risk for distress (Carleton, 2016; McEvoy \& Mahoney, 2012) —at least in part by reducing the capacity for mindful presence in the face of uncertain stressors (Kraemer et al., 2016) - that can be screened for and ameliorated through appropriate preventive interventions (Einstein, 2014; Furtado et al., 2019). Further study of these risk paths may inform the development and use of "mechanistically informed and driven" interventions that are needed to address psychological distress due to the pandemic (Holmes et al., 2020).

Guided by the needs identified above, the current investigation aims to identify (1) how IU and perceived change in mindfulness during the pandemic relate to perinatal mothers' psychological symptoms and (2) whether there is an indirect effect of IU on maternal psychological symptoms transmitted through perceived reductions in mindfulness. We hypothesize that both high IU and perceived decrease in mindfulness during COVID-19 will be associated with elevated symptoms and that there will be a significant indirect effect of IU on maternal psychological symptoms through a perceived decrease in mindfulness. Testing these paths in a cross-sectional study is not a true test of mediated or causal effects; thus, in the current study, the term "indirect effect" is used as a statistical term referring to the test of the AB path. The current study will test whether there is a pattern of associations that is consistent with the proposed theoretical model, building toward more definitive tests that will help clarify the conditions most likely to negatively impact mothers and potentially harm the development of children born in the pandemic and target opportunities to intervene before harms to mother, child, and family well-being accumulate.

\section{Method}

\section{Participants}

Participants were 199 English-speaking pregnant people $(66.8 \%, n=133)$ or new mothers who had given birth in the past 6 months $(33.2 \%, n=66)$. Participants' ages ranged from 20.6 to
$47.5(M=33.3, S D=4.4)$. For almost half of participants (48.7\%, $n=97)$, this was their first pregnancy, and $49 \%(n=96)$ of participants had no other children living in their household, 35.2\% had one other child $(n=69)$, and $15.8 \%$ had two or more $(n=31)$. Ninety-seven percent of pregnancies were singletons $(n=193$; twins: $3 \%, n=6)$. This sample was $85.4 \%$ White $(n=170), 7 \%$ Hispanic or Latino $(n=14), 2.5 \%$ Asian $(n=5), 2 \%$ Black/African American $(n=4)$, and $1 \%$ Native American/Alaskan $(n=2)$. The majority of participants were socioeconomically advantaged (median income \$100,000-\$120,000; 87.9\% with a college degree $[n=175])$ and married or partnered $(96 \%, n=191)$.

\section{Procedure}

The measures of interest in the current study were drawn from the Early Parenthood in COVID-19 (EPiC) online study (Laurent et al., 2021), which includes multiple measures of the perinatal experience and was based on the COVID-19 and Perinatal Experiences (COPE) Survey (VanTieghem et al., 2020). Participants were recruited for the EPiC study via social media targeted to residents of Illinois and email to participants of larger ongoing studies of pregnant individuals and new mothers in Illinois to participate in an online survey administered through REDCap (Research Electronic Data Capture; Harris et al., 2009). All participants gave informed consent before participating in the EPiC study. For every 50 participants, a random lottery selected a participant to receive a $\$ 100$ gift certificate. Data collection began in May 2020, with results below reflecting responses through September 14, 2020. All procedures were approved by the University of Illinois Institutional Review Board. Participants were eligible for this study if they were currently pregnant or had given birth within the last six months. Participants with incomplete data on the measures of interest were excluded from the current analysis.

\section{Measures}

The EPiC online questionnaire included a larger set of items assessing participants' demographic background and the impact of the COVID-19 outbreak on the feelings and experiences of pregnant individuals and new mothers. Scales relevant to the constructs of interest for the current study are described below (see Table 1 for descriptive statistics).

\section{Intolerance of Uncertainty}

The Intolerance of Uncertainty Scale (IUS-12; Carleton et al., 2007) is a 12-item self-report measure examining beliefs about the acceptability of uncertainty or 
Table 1 Means, standard deviations, and correlations with confidence intervals of study variables

\begin{tabular}{lrrlll}
\hline Variable & \multicolumn{1}{c}{$M$} & \multicolumn{1}{c}{$S D$} & \multicolumn{1}{c}{1} & 2 & 3 \\
\hline 1. IU & 33.15 & 8.60 & - & & \\
2. BSI total & 28.28 & 10.60 & $.45^{* *}[.33, .56]$ & - & \\
3. Pre-COVID FFMQ & 3.40 & 0.41 & $-.40^{* *}[-.51,-.28]$ & $-.26^{* *}[-.39,-.13]$ & - \\
4. COVID FFMQ & 3.22 & 0.47 & $-.45^{* *}[-.55,-.33]$ & $-.56^{* *}[-.65,-.46]$ & $.69^{* *}[.61, .75]$ \\
\hline
\end{tabular}

Note. BSI, Brief Symptom Inventory; FFMQ, Five Facet Mindfulness Questionnaire; IU, Intolerance of Uncertainty Scale. $M$ and $S D$ are used to represent unstandardized mean and standard deviation, respectively. Values in square brackets indicate the $95 \%$ confidence interval for each correlation

*Indicates $p<.05$

**Indicates $p<.01$

unpredictability (e.g., "Unforeseen events upset me greatly"). Items were rated a scale from 1 ("Not at all characteristic of me") to 5 ("Entirely characteristic of me") and were summed to obtain a total score with higher scores indicating greater IU $(\alpha=0.91)$.

\section{Mindfulness}

The Five Facet Mindfulness Questionnaire-Short Form (FFMQ-SF; Bohlmeijer et al., 2011) is a 24-item measure assessing five dimensions of mindfulness: observing, describing, acting with awareness, nonjudgment, and nonreactivity. An example item is, "When I have distressing thoughts or images, I just notice them and let them go." Participants rated each item twice- "before the COVID-19 pandemic" and "during the COVID-19 pandemic"-to obtain their perceptions of both their pre-pandemic and current pandemic mindfulness; similar to previous studies of perinatal samples that assessed pre-pandemic and current self-report scores during COVID-19 (Davenport et al., 2020). Items are rated on a scale from 1 ("Never or very rarely true") to 5 ("Very often or always true") and were averaged to obtain a total retrospective pre-pandemic mindfulness score and a total current pandemic mindfulness score. Higher scores indicate greater self-assessed mindfulness during the specified time period $(\alpha=0.79-0.84)$.

\section{Psychological Symptoms}

The 18-item version of the Brief Symptom Inventory (BSI18; Zabora et al., 2001) assesses psychological symptoms, that is, depression ("Feeling blue"), anxiety ("Feeling tense or keyed up"), and somatization ("Nausea or upset stomach"). Due to the online format of this study, the item assessing suicide (i.e., "Thoughts of ending your life") was removed. The items were scored on a Likert scale of 0 ("Not at all") to 4 ("Extremely"). Responses were summed to create a total score used in analyses where high scores indicate greater symptoms $(\alpha=0.92)$.

\section{Data Analyses}

The SPSS PROCESS macro (model 4; Hayes, 2009) was used to test both direct associations between standardized scores of mindfulness, IU, and psychological symptoms and the proposed indirect effect of IU on total BSI scores via a perceived change in FFMQ mindfulness during the pandemic. To capture perceived change in mindfulness during COVID-19, pandemic FFMQ scores were analyzed controlling for pre-pandemic scores; this residualized change score is drawn from previous methods for studying changes in mindfulness (Brown \& Ryan, 2003; Kumar et al., 2008). Ten thousand bootstrap samples were used to arrive at the 95\% confidence interval for parameter estimates.

\section{Results}

\section{Direct Associations}

The total effect of IU $(b=0.46, S E=0.064 ; p<0.001)$ on psychological symptoms was significant (model $R^{2}=0.21$; $F[1,201]=52.81, p<0.001)$. The total effect of decreased mindfulness during the pandemic $(b=-0.72, S E=0.08$; $p<0.001)$ on psychological symptoms was significant when controlling for pre-pandemic mindfulness (model $R^{2}=0.34$; $F[2,197]=51.13, p<0.001)$.

\section{Indirect Effects}

The full model revealed a significant, though smaller, direct effect IU $(b=0.29, S E=0.063 ; 95 \%$ CI $[0.16,0.41])$ on symptoms along with a significant indirect effect via perceived decrease in mindfulness during the pandemic ( $b=0.13, S E=0.043 ; 95 \%$ CI $[0.060,0.226])$. This overall model explained a sizable proportion of the variance in symptoms $\left(R^{2}=0.41 ; F[3,195]=45.08, p<0.001\right)$, see Fig. 1 for full model effects. A post hoc power analysis 
Fig. 1 Full model results. Pre-COVID mindfulness was included as a covariate but is not represented here. $*$ indicates $p<.05$. ** indicates $p<.01$

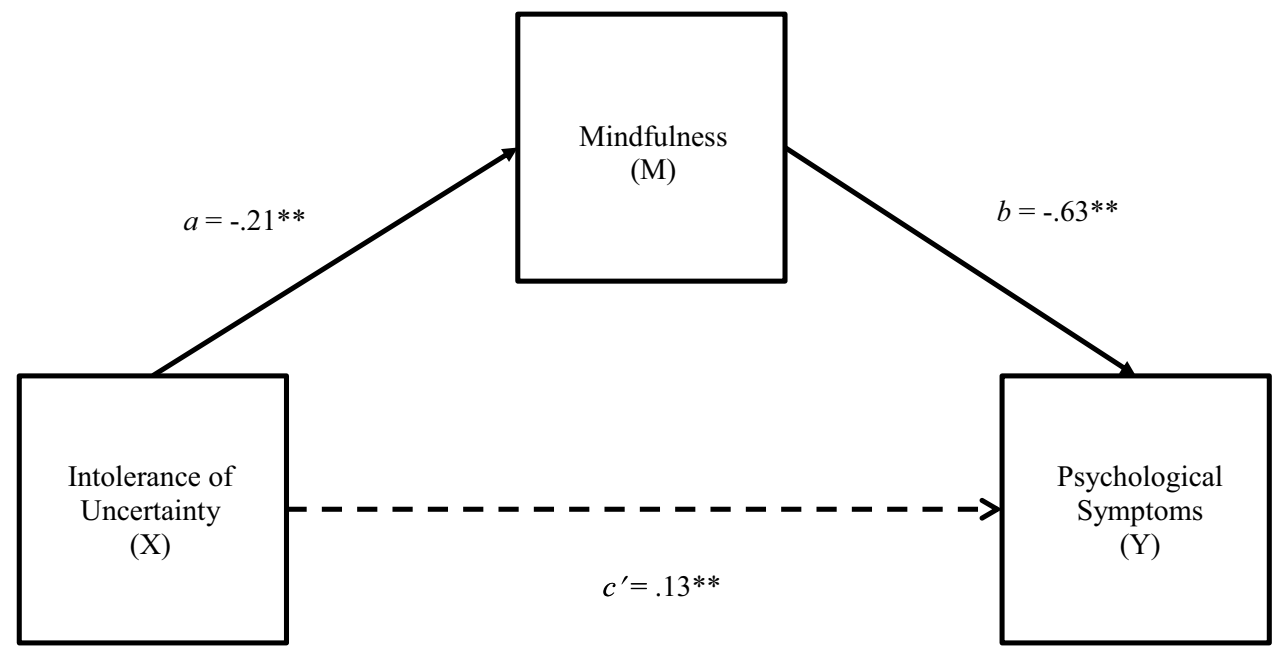

conducted using MedPower (Kenny, 2017) based on the sample size of 199, effects for each path, and an alpha of 0.05 indicated adequate power (0.847) to detect indirect effects.

To further probe which facets of mindfulness drove these indirect effects, mediation analyses were conducted on each of the FFMQ subscales. The indirect effect of IU on symptoms was significant through three subscales: acting with awareness $(b=0.07, S E=0.030 ; 95 \%$ CI [0.023, $0.141])$, nonreactivity $(b=0.07, S E=0.036 ; 95 \%$ CI [0.01, $0.15])$, and describing $(b=0.07, S E=0.032 ; 95 \%$ CI $[0.01$ to 0.14$])\left(\operatorname{model} R^{2} \mathrm{~s}=0.30-0.38 ; F[3,195]=27.15-39.52\right.$, $p<0.001)$.

Further post hoc analyses were conducted with BSI depression and anxiety as separate outcomes to probe specificity to symptom domain. With depression as an outcome, a significant direct effect of IU $(b=0.28, S E=0.064 ; 95 \%$ CI $[0.15,0.40])$ on depression symptoms was found in addition to a significant indirect effect via decreased pandemic FFMQ ratings $(b=0.13, S E=0.04 ; 95 \%$ CI [0.061, 0.220]; $\left.R^{2}=0.38 ; F[3,195]=39.98, p<0.001\right)$. When anxiety was entered as an outcome, mediation analyses similarly showed a significant direct effect of IU $(b=0.30, S E=0.063$; $95 \%$ CI $[0.17,0.42])$ on anxiety symptoms and a significant indirect effect via decreased pandemic FFMQ ratings $\left(b=0.12, S E=0.04 ; 95 \%\right.$ CI $[0.053,0.211] ; R^{2}=0.39 ; F[3$, $195]=40.89, p<0.001)$.

\section{Discussion}

The current study aimed to shed light on paths to psychological symptoms in parents who bear and begin rearing a child in the challenging environment of the COVID-19 pandemic. As hypothesized, high IU and a perceived reduction in mindfulness during the pandemic were associated with elevated psychological symptoms. There was also, in line with our second hypothesis, a significant indirect effect of IU on maternal psychological symptoms through a perceived decrease in mindfulness qualities-in particular, nonreactivity, acting with awareness, and describing facets of dispositional mindfulness. The indirect effects of these facets driving the overall effect were similar in magnitude and small according to effect size conventions (Cohen, 1992). At least in this study, the indirect effect of IU on symptoms through a perceived reduction in mindfulness was strongest and most apparent when considering all elements of mindfulness working together as opposed to individual facets. In line with indications from previous research outside a pandemic and/or perinatal context (Nekić \& Mamić, 2019), these results suggest mothers who are less able to tolerate uncertainty experience more psychological symptoms, in part due to a sense of diminished mindfulness during the pandemic.

These results extend previous work implicating both IU and low mindfulness in elevated psychological symptoms (Brown et al., 2015; Yook et al., 2010) and processes known to maintain anxiety and depression (Deyo et al., 2009; Lotan et al., 2013; Yook et al., 2010) while offering a useful frame for conceptualizing how these may be perpetuated (or interrupted) in the current pandemic. These findings, specifically the post hoc analyses including the depression and anxiety symptom subscales of the BSI, echo previous research showing concurrent mindful attention partially mediated the predictive relationship between IU and depression and anxiety symptoms in a sample of female students in Croatia (Nekić \& Mamić, 2019). The current study extends these findings to expectant/new mothers in a particularly uncertain global context, suggesting that mothers who are able to tolerate uncertainty may have more access to mindfulness as an emotion regulation strategy in the face of unpredictable 
and potentially overwhelming circumstances, helping them to view negative emotional reactions from a decentered, accepting, and nonreactive perspective. As a result, they may perceive these aversive emotional states as less threatening and more bearable, interrupting the cycle of worry, rumination, and prolonged negative affect that maintain both anxiety and depression symptoms.

These findings are in line with previous research in perinatal populations, which shows that IU predicts poor mental health in mother and child (Aktar et al., 2017; Furtado et al., 2019), whereas mindfulness can promote well-being (e.g., Duncan et al., 2009; Hicks et al., 2018). The current results help to understand how IU functions as an instrumental risk factor in the development and maintenance of psychological symptoms; IU may make it more difficult to engage in adaptive coping/emotion regulation strategies such as mindfulness, thereby increasing sensitivity to stress and likelihood of distress in a climate of uncertainty. Our findings point to particular aspects of mindfulness that may be key to maintaining parental well-being in such a climate, underlining the importance of maintaining the ability to be present with experience as it unfolds without becoming lost in emotional reactivity. This is consistent with previous findings that nonreactivity and openness to experience can buffer stressrelated distress (see Hamill et al., 2015; Lindsay, Chin, et al., 2018; Lindsay, Young, et al., 2018; O'Bryan et al., 2018). By promoting openness and flexible responding to changing conditions, mindfulness could help parents foster the supportive environment they and their baby need to maintain healthy stress sensitivity and regulation (Laurent, 2014) and satisfying familial relationships (Barnes et al., 2007; Duncan et al., 2009) in the face of uncontrollable shifts in resources and threats. The current findings thus highlight risk factors that warrant additional research to examine their utility to guide screening for early risk detection and selection of interventions well suited to target such factors in an effort to prevent elevated psychological symptoms in expectant and new mothers amid the mental health crisis for new parents (i.e., COVID-19; Grose, 2020).

Our findings identify IU as a precipitating risk factor for psychological distress in expectant and new mothers (Grose, 2020), a risk factor that has been implicated in the intergenerational transmission of mental illness (Aktar et al., 2017). This research can inform future investigations of IU as a guide in screening for early risk detection and as a proposed modifiable risk factor that may be targeted by psychological interventions during the current pandemic and during future global stress events (Rettie \& Daniels, 2020). When misperceptions about absent information cannot be corrected (e.g., as knowledge about the nature and impacts of this novel coronavirus is being generated), future research is warranted to further investigate whether this risk factor may best be addressed through interventions that increase an individual's ability to cope with and tolerate aversive responses caused by uncertainty.

Mindfulness-based interventions may be uniquely poised to address IU as a cost- and time-effective strategy to decrease parents' mental health risk during uncertain global stress events such as the COVID-19 pandemic (Chen et al., 2021). In addition to mindfulness-based interventions' promotion of healthy coping strategies, mindfulness may directly target IU through an emphasis on nonattachment and letting go of the need for certainty. Mindfulness-based interventions have further been shown to impact processes by which IU leads to distress-that is, by decreasing worry and rumination (Deyo et al., 2009; Ma \& Teasdale, 2004), increasing distress tolerance (Lotan et al., 2013), and fostering acceptance and nonreactivity in the face of negative situations and emotions (Lindsay, Chin, et al., 2018; Lindsay, Young, et al., 2018). Furthermore, due to COVID, utilization of telehealth has increased and there are greater options for mindfulnessbased interventions to be accessed remotely through online programs in addition to pre-existing apps (e.g., Calm, Headspace, Insight Timer; Huberty et al., 2019). These electronic options increase accessibility both generally during a pandemic and specifically for new parents who may have difficulty attending an in-person class, and meta-analytic evidence supports the effectiveness of online mindfulness-based interventions for mental health (Spijkerman et al., 2016).

This study represents part of a broader effort to inform the selection of "mechanistically informed and driven" risk factors and interventions to address psychological needs during the pandemic (Holmes et al., 2020); this need is especially great in perinatal populations given both heightened vulnerability to mental health concerns and the known negative impact of poor perinatal mental health on maternal, infant, and family well-being over time. During this pandemic, or in future times of great uncertainty, future research should examine the utility of screening child-bearers and new mothers for elevated IU and providing access to interventions, such as mindfulness training, that have been demonstrated to improve tolerance of uncertainty and foster effective coping strategies to improve mothers' and their family's well-being.

\section{Limitations and Future Research}

There are several limitations to this research. First, data were collected at one timepoint via an online, self-report survey, which required retrospective report of pre-pandemic mindfulness. These limitations restricted our ability to infer causal relationships, measure change over time, and draw conclusions that could inform clinical use on the basis of the current findings. Longitudinal studies with a randomized intervention component are needed to better understand how IU and mindfulness impact psychological symptoms over time, especially during global stress events. 
Second, our sample was relatively privileged and homogenous in race, socioeconomic status, and education. They were predominantly White, upper to upper-middle class, and college educated, which may reflect biases in our recruitment strategies and who had access and time to complete an uncompensated survey in a pandemic. It is possible that the current sample represented higher IU and/or stronger effects of IU because their socioeconomic status had shielded them from uncertainty related to financial or resource insecurity prior to the pandemic. It will be important to test the currently detected paths in more diverse samples that include parents with pre-existing vulnerabilities such as economic hardship and experiences of racism and marginalization who are at greater risk of psychological distress during COVID19 (Prime et al., 2020) to determine if the same risk paths and attendant screening/intervention recommendations apply. For now, our findings provide insight into processes that can exacerbate or alleviate distress in a group expected to be protected against the worst harms of the pandemic, and underline the fact that the multiple stressors posed by COVID-19 exert widespread effects on the population.

Third, the survey began 2 months after the rise of COVID-19 in the United States and the beginning of quarantine and social distancing guidelines. It is possible that at the beginning of the pandemic, researchers might have observed different intensities of COVID-related fears, IU, perceived mindfulness shifts, and psychological symptoms or resilience. However, our findings provide evidence for the ongoing negative impact of COVID-19 in the United States. The negative effects of this pandemic were not just due to initial shock and upheaval; COVID-19 continues to adversely impact expectant and new mothers, and this study provides a window into the cumulative impact of an evolving constellation of stressors (with a still uncertain end) on mothers' well-being.

Lastly, measures in the current study utilized the same method of data collection; thus, common method bias is a limitation of the current study as a source of potential measurement error. Constructs were measured by participants' responses to self-report questionnaires at the same time, which could in part elicit stronger observed associations between variables due to common method variance (e.g., common rater effects, common scale formats, measurement context formats, social desirability, or priming effects) rather than the sheer correlation of the constructs (Podsakoff et al., 2003). Future research may control for common method bias by introducing a time lag between measurement of the variables of interest, counterbalancing item order, or by obtaining multiple measures of the variables via different methods (e.g., self-reported psychological symptoms, collateral report of psychological symptoms, and/or clinical interview; Campbell \& Fiske, 1959; Podsakoff et al., 2003).
The current study provides support for IU and perceived diminishing mindfulness in paths to psychological wellbeing among parents during the COVID-19 pandemic. Our results suggest mothers who are less able to tolerate uncertainty experience more psychological symptoms, in part due to perceived reduction in mindfulness during the pandemic. This finding points to IU as a modifiable risk factor for parental distress in the face of the pandemic and mindfulness as a mechanism that could be targeted to improve family outcomes. These results support the use of IU in screening for risk and mindfulness-based interventions to address IU and psychological distress in expectant mothers, especially during pandemics or similar events.

Author Contributions M.D.S. created research questions, conducted analyses, wrote the majority of article text, and coordinated efforts of co-authors. K.H. created the online questionnaire, assisted in analyses, and contributed to manuscript preparation. H.K.L. supervised the current study, provided intellectual inputs, and assisted in project development, analyses, and manuscript preparation. All authors read and approved the manuscript.

Data availability Once data collection for the larger EPiC study is complete, the data for the current study will be available at the Open Science Framework (https://osf.io/5khws/), expected release: Fall 2021.

\section{Declarations}

Ethics Approval and Consent to Participate All procedures performed in studies involving human participants were in accordance with the ethical standards of the institutional and/or national research committee and with the 1964 Helsinki declaration and its later amendments or comparable ethical standards. All procedures were approved by the University of Illinois Institutional Review Board and informed consent was obtained from all participants prior to study participation.

Conflict of Interest The authors declare no competing interests.

\section{References}

Aktar, E., Nikolić, M., \& Bögels, S. M. (2017). Environmental transmission of generalized anxiety disorder from parents to children Worries experiential avoidance and intolerance of uncertainty. Dialogues in Clinical Neuroscience, 19(2), 137-147. https://doi. org/10.31887/DCNS.2017.19.2/eaktar

American Psychological Association. (2020). Stress in America ${ }^{T M}$ 2020: Stress in the Time of COVID-19 (Vol. 1). https://www. apa.org/news/press/releases/stress/2020/stress-in-americacovid.pdf

Barnes, S., Brown, K. W., Krusemark, E., Campbell, W. K., \& Rogge, R. D. (2007). The role of mindfulness in romantic relationship satisfaction and responses to relationship stress. Journal of Marital and Family Therapy, 33(4), 482-500. https://doi.org/10.1111/j. 1752-0606.2007.00033.x

Baumrind, D. (1989). Rearing competent children. In W. Damon (Ed.), Child development today and tomorrow (pp. 349-378). Jossey-Bass. 
Beck, C. T. (1999). Postpartum depression: Stopping the thief that steals motherhood. AWHONN Lifelines, 3(4), 41-44. https://doi. org/10.1111/j.1552-6356.1999.tb01115.x

Belen, H. (2021). Fear of COVID-19 and mental health: The role of mindfulness in during times of crisis. International Journal of Mental Health and Addiction. https://doi.org/10.1007/ s11469-020-00470-2

Bohlmeijer, E., ten Klooster, P. M., Fledderus, M., Veehof, M., \& Baer, R. (2011). Psychometric properties of the five facet mindfulness questionnaire in depressed adults and development of a short form. Assessment, 18(3), 308-320. https://doi.org/10.1177/ 1073191111408231

Boswell, J. F., Thompson-Hollands, J., Farchione, T. J., \& Barlow, D. H. (2013). Intolerance of uncertainty: A common factor in the treatment of emotional disorders. Journal of Clinical Psychology, 69(6), 630-645. https://doi.org/10.1002/jclp.21965

Braeken, M. A. K. A., Jones, A., Otte, R. A., Nyklíček, I., \& Van den Bergh, B. R. H. (2017). Potential benefits of mindfulness during pregnancy on maternal autonomic nervous system function and infant development. Psychophysiology, 54(2), 279-288. https:// doi.org/10.1111/psyp. 12782

Brand, S. R., \& Brennan, P. A. (2009). Impact of antenatal and postpartum maternal mental illness: How are the children? Clinical Obstetrics \& Gynecology, 52(3), 441-455. https://doi.org/10. 1097/GRF.0b013e3181b52930

Brooks, S. K., Weston, D., \& Greenberg, N. (2020). Psychological impact of infectious disease outbreaks on pregnant women: Rapid evidence review. Public Health, 189, 26-36. https://doi.org/10. 1016/j.puhe.2020.09.006

Brown, D. B., Bravo, A. J., Roos, C. R., \& Pearson, M. R. (2015). Five facets of mindfulness and psychological health: Evaluating a psychological model of the mechanisms of mindfulness. Mindfulness, 6(5), 1021-1032. https://doi.org/10.1007/s12671-014-0349-4

Brown, K. W., \& Ryan, R. M. (2003). The benefits of being present: Mindfulness and its role in psychological well-being. Journal of Personality and Social Psychology, 84(4), 822-848. https://doi. org/10.1037/0022-3514.84.4.822

Buhr, K., \& Dugas, M. J. (2002). The intolerance of uncertainty scale: Psychometric properties of the English version. Behaviour Research and Therapy, 40(8), 931-945. https://doi.org/10.1016/ S0005-7967(01)00092-4

Campbell, D. T., \& Fiske, D. W. (1959). Convergent and discriminant validation by the multitrait-multimethod matrix. Psychological Bulletin, 56(2), 81-105. https://doi.org/10.1037/h0046016

Carleton, R. N. (2012). The intolerance of uncertainty construct in the context of anxiety disorders: Theoretical and practical perspectives. Expert Review of Neurotherapeutics, 12(8), 937-947. https://doi.org/10.1586/ern.12.82

Carleton, R. N. (2016). Into the unknown: A review and synthesis of contemporary models involving uncertainty. Journal of Anxiety Disorders, 39, 30-43. https://doi.org/10.1016/j.janxdis.2016.02. 007

Carleton, R. N., Norton, M. A. P. J., \& Asmundson, G. J. G. (2007). Fearing the unknown: A short version of the Intolerance of Uncertainty Scale. Journal of Anxiety Disorders, 21(1), 105-117. https://doi.org/10.1016/j.janxdis.2006.03.014

Center for Translational Neuroscience at the University of Oregon. (2020, August 12). How long can the levee hold?: The role of caregiver emotional support in buffering children from the stress of material hardship Medium. https://medium.com/rapid-ec-proje ct/how-long-can-the-levee-hold-2a2cd0779914

Ceulemans, M., Hompes, T., \& Foulon, V. (2020). Mental health status of pregnant and breastfeeding women during the COVID-19 pandemic: A call for action. International Journal of Gynecology \& Obstetrics, 151(1), 146-147. https://doi.org/10.1002/ijgo.13295
Chen, H., Selix, N., \& Nosek, M. (2021). Perinatal anxiety and depression during COVID-19. The Journal for Nurse Practitioners, 17(1), 26-31. https://doi.org/10.1016/j.nurpra.2020.09.014

Cohen, J. (1992). A power primer. Psychological Bulletin, 112(1), 155-159. https://doi.org/10.1037/0033-2909.112.1.155

Cullen, W., Gulati, G., \& Kelly, B. D. (2020). Mental health in the COVID-19 pandemic. QJM An International Journal of Medicine, 113(5), 311-312. https://doi.org/10.1093/qjmed/hcaa110

Davenport, M. H., Meyer, S., Meah, V. L., Strynadka, M. C., \& Khurana, R. (2020). Moms are not OK: COVID-19 and maternal mental health. Frontiers in Global Women's Health, 1.https://doi. org/10.3389/fgwh.2020.00001

Deyo, M., Wilson, K. A., Ong, J., \& Koopman, C. (2009). Mindfulness and rumination: Does mindfulness training lead to reductions in the ruminative thinking associated with depression? EXPLORE, 5(5), 265-271. https://doi.org/10.1016/j.explore.2009.06.005

Dugas, M. J., Gagnon, F., Ladouceur, R., \& Freeston, M. H. (1998). Generalized anxiety disorder: A preliminary test of a conceptual model. Behaviour Research and Therapy, 36(2), 215-226. https:// doi.org/10.1016/S0005-7967(97)00070-3

Dugas, M. J., Gosselin, P., \& Ladouceur, R. (2001). Intolerance of uncertainty and worry: Investigating specificity in a nonclinical sample. Cognitive Therapy and Research, 25(5), 551-558. https:// doi.org/10.1023/A:1005553414688

Duncan, L. G., Coatsworth, J. D., \& Greenberg, M. T. (2009). A model of mindful parenting: Implications for parent-child relationships and prevention research. Clinical Child and Family Psychology Review, 12(3), 255-270. https://doi.org/10.1007/ s10567-009-0046-3

Einstein, D. A. (2014). Extension of the transdiagnostic model to focus on intolerance of uncertainty: A review of the literature and implications for treatment. Clinical Psychology: Science and Practice, 21(3), 280-300. https://doi.org/10.1111/cpsp.12077

Ellington, S., Strid, P., Tong, V. T., Woodworth, K., Galang, R. R., Zambrano, L. D., Nahabedian, J., Anderson, K., \& Gilboa, S. M. (2020). Characteristics of women of reproductive age with laboratory-confirmed SARS-CoV-2 infection by pregnancy status-United States, January 22-June 7, 2020. Morbidity and Mortality Weekly Report, 69(25), 769-775. https://doi.org/10.15585/ mmwr.mm6925a1

Fairbrother, N., Young, A. H., Janssen, P., Antony, M. M., \& Tucker, E. (2015). Depression and anxiety during the perinatal period. BMC Psychiatry, 15(1), 206. https://doi.org/10.1186/ s12888-015-0526-6

Fernandes, D. V., Canavarro, M. C., \& Moreira, H. (2021). The mediating role of parenting stress in the relationship between anxious and depressive symptomatology, mothers' perception of infant temperament, and mindful parenting during the postpartum period. Mindfulness, 12, 275-290. https://doi.org/10.1007/ s12671-020-01327-4

Freeston, M., Tiplady, A., Mawn, L., Bottesi, G., \& Thwaites, S. (2020). Towards a model of uncertainty distress in the context of Coronavirus (COVID-19). The Cognitive Behaviour Therapist. https://doi.org/10.1017/S1754470X2000029X

Furtado, M., Van Lieshout, R. J., Van Ameringen, M., Green, S. M., \& Frey, B. N. (2019). Biological and psychosocial predictors of anxiety worsening in the postpartum period: A longitudinal study. Journal of Affective Disorders, 250, 218-225. https://doi.org/10. 1016/j.jad.2019.02.064

Gambrel, L. E., \& Piercy, F. P. (2015). Mindfulness-based relationship education for couples expecting their first child-Part 1: A randomized mixed-methods program evaluation. Journal of Marital and Family Therapy, 41(1), 5-24. https://doi.org/10.1111/jmft. 12066

Gentes, E. L., \& Ruscio, A. M. (2011). A meta-analysis of the relation of intolerance of uncertainty to symptoms of generalized anxiety 
disorder, major depressive disorder, and obsessive-compulsive disorder. Clinical Psychology Review, 31(6), 923-933. https://doi. org/10.1016/j.cpr.2011.05.001

Grose, J. (2020, September 9). The pandemic is a 'mental health crisis' for parents. The New York Times. https://www.nytimes.com/2020/ 09/09/parenting/mental-health-parents-coronavirus.html

Hamill, T. S., Pickett, S. M., Amsbaugh, H. M., \& Aho, K. M. (2015). Mindfulness and acceptance in relation to behavioral inhibition system sensitivity and psychological distress. Personality and Individual Differences, 72, 24-29. https://doi.org/10.1016/j.paid. 2014.08.007

Harris, P. A., Taylor, R., Thielke, R., Payne, J., Gonzalez, N., \& Conde, J. G. (2009). Research electronic data capture (REDCap)—A metadata-driven methodology and workflow process for providing translational research informatics support. Journal of Biomedical Informatics, 42(2), 377-381. https://doi.org/10.1016/j. jbi.2008.08.010

Hayes, A. F. (2009). Beyond Baron and Kenny: Statistical mediation analysis in the new millennium. Communication Monographs, 76(4), 408-420. https://doi.org/10.1080/03637750903310360

Hicks, L. M., Dayton, C. J., Brown, S., Muzik, M., \& Raveau, H. (2018). Mindfulness moderates depression and quality of prenatal attachment in expectant parents. Mindfulness, 9(5), 1604-1614. https://doi.org/10.1007/s12671-018-0907-2

Holmes, E. A., O'Connor, R. C., Perry, V. H., Tracey, I., Wessely, S., Arseneault, L., Ballard, C., Christensen, H., Silver, R. C., Everall, I., Ford, T., John, A., Kabir, T., King, K., Madan, I., Michie, S., Przybylski, A. K., Shafran, R., Sweeney, A., ... Bullmore, E. (2020). Multidisciplinary research priorities for the COVID19 pandemic: A call for action for mental health science. The Lancet Psychiatry, 7(6), 547-560. https://doi.org/10.1016/S22150366(20)30168-1

Howard, L. M., Molyneaux, E., Dennis, C.-L., Rochat, T., Stein, A., \& Milgrom, J. (2014). Non-psychotic mental disorders in the perinatal period. The Lancet, 384(9956), 1775-1788. https://doi.org/ 10.1016/S0140-6736(14)61276-9

Huberty, J., Green, J., Glissmann, C., Larkey, L., Puzia, M., \& Lee, C. (2019). Efficacy of the mindfulness meditation mobile app "Calm" to reduce stress among college students Randomized controlled trial. JMIR MHealth and UHealth, 7, 6. https://doi. org/10.2196/14273

Kabat-Zinn, J. (2003). Mindfulness-based interventions in context: Past, present, and future. Clinical Psychology: Science and Practice, 10(2), 144-156. https://doi.org/10.1093/clipsy.bpg016

Kenny, D. A. (2017). MedPower: An interactive tool for the estimation of power in tests of mediation. https://davidakenny.shinyapps.io/ MedPower/

Kingston, D., Tough, S., \& Whitfield, H. (2012). Prenatal and postpartum maternal psychological distress and infant development: A systematic review. Child Psychiatry \& Human Development, 43(5), 683-714. https://doi.org/10.1007/s10578-012-0291-4

Kraemer, K. M., O’Bryan, E. M., \& McLeish, A. C. (2016). Intolerance of uncertainty as a mediator of the relationship between mindfulness and health anxiety. Mindfulness, 7(4), 859-865. https://doi. org/10.1007/s12671-016-0524-x

Kumar, S., Feldman, G., \& Hayes, A. (2008). Changes in mindfulness and emotion regulation in an exposure-based cognitive therapy for depression. Cognitive Therapy and Research, 32(6), 734-744. https://doi.org/10.1007/s10608-008-9190-1

Laurent, H. K. (2014). Clarifying the contours of emotion regulation: Insights from parent-child stress research. Child Development Perspectives, 8(1), 30-35. https://doi.org/10.1111/cdep.12058

Laurent, H. K., Duncan, L. G., Lightcap, A., \& Khan, F. (2017). Mindful parenting predicts mothers' and infants' hypothalamicpituitary-adrenal activity during a dyadic stressor. Developmental Psychology, 53(3), 417-424. https://doi.org/10.1037/dev0000258
Laurent, H. K., Sbrilli, M. D., Haigler, K., Danyelle, D. N., \& Finnegan, M. (2021, March 4). EPiC (Early Parenthood in COVID-19) Study. Retrieved from osf.io/5khws

Lebel, C., MacKinnon, A., Bagshawe, M., Tomfohr-Madsen, L., \& Giesbrecht, G. (2020). Elevated depression and anxiety symptoms among pregnant individuals during the COVID-19 pandemic. Journal of Affective Disorders, 277, 5-13. https:// doi.org/10.1016/j.jad.2020.07.126

Letourneau, N., Salmani, M., \& Duffett-Leger, L. (2010). Maternal depressive symptoms and parenting of children from birth to 12 years. Western Journal of Nursing Research, 32(5), 662-685. https://doi.org/10.1177/0193945909359409

Liao, K.Y.-H., \& Wei, M. (2011). Intolerance of uncertainty, depression, and anxiety: The moderating and mediating roles of rumination. Journal of Clinical Psychology, 67(12), 1220-1239. https:// doi.org/10.1002/jclp.20846

Lindsay, E. K., Chin, B., Greco, C. M., Young, S., Brown, K. W., Wright, A. G. C., Smyth, J. M., Burkett, D., \& Creswell, J. D. (2018). How mindfulness training promotes positive emotions: Dismantling acceptance skills training in two randomized controlled trials. Journal of Personality and Social Psychology, 115(6), 944-973. https://doi.org/10.1037/pspa0000134

Lindsay, E. K., Young, S., Smyth, J. M., Brown, K. W., \& Creswell, J. D. (2018). Acceptance lowers stress reactivity: Dismantling mindfulness training in a randomized controlled trial. Psychoneuroendocrinology, 87, 63-73. https://doi.org/10.1016/j.psyne uen.2017.09.015

López-Morales, H., del Valle, M. V., Canet-Juric, L., Andrés, M. L., Galli, J. I., Poó, F., \& Urquijo, S. (2021). Mental health of pregnant women during the COVID-19 pandemic: A longitudinal study. Psychiatry Research, 295, 113567. https://doi.org/10. 1016/j.psychres.2020.113567

Lotan, G., Tanay, G., \& Bernstein, A. (2013). Mindfulness and distress tolerance: Relations in a mindfulness preventive intervention. International Journal of Cognitive Therapy, 6(4), 371-385. https://doi.org/10.1521/ijct.2013.6.4.371

Ma, S. H., \& Teasdale, J. D. (2004). Mindfulness-based cognitive therapy for depression: Replication and exploration of differential relapse prevention effects. Journal of Consulting and Clinical Psychology, 72(1), 31-40. https://doi.org/10.1037/0022-006X. 72.1 .31

Madigan, S., Oatley, H., Racine, N., Fearon, R. M. P., Schumacher, L., Akbari, E., Cooke, J. E., \& Tarabulsy, G. M. (2018). A metaanalysis of maternal prenatal depression and anxiety on child socioemotional development. Journal of the American Academy of Child \& Adolescent Psychiatry, 57(9), 645-657.e8. https://doi. org/10.1016/j.jaac.2018.06.012

McEvoy, P. M., Hyett, M. P., Shihata, S., Price, J. E., \& Strachan, L. (2019). The impact of methodological and measurement factors on transdiagnostic associations with intolerance of uncertainty: A meta-analysis. Clinical Psychology Review, 73, 101778. https:// doi.org/10.1016/j.cpr.2019.101778

McEvoy, P. M., \& Mahoney, A. E. J. (2012). To be sure, to be sure: Intolerance of uncertainty mediates symptoms of various anxiety disorders and depression. Behavior Therapy, 43(3), 533-545. https://doi.org/10.1016/j.beth.2011.02.007

Meltzer-Brody, S., Howard, L. M., Bergink, V., Vigod, S., Jones, I., Munk-Olsen, T., Honikman, S., \& Milgrom, J. (2018). Postpartum psychiatric disorders. Nature Reviews Disease Primers, 4(1), 18022. https://doi.org/10.1038/nrdp.2018.22

Miller, R. L., Pallant, J. F., \& Negri, L. M. (2006). Anxiety and stress in the postpartum: Is there more to postnatal distress than depression? BMC Psychiatry, 6(1), 12. https://doi.org/10.1186/ 1471-244X-6-12

Mughal, M. K., Giallo, R., Arnold, P. D., Kehler, H., Bright, K., Benzies, K., Wajid, A., \& Kingston, D. (2019). Trajectories of 
maternal distress and risk of child developmental delays: Findings from the All Our Families (AOF) pregnancy cohort. Journal of Affective Disorders, 248, 1-12. https://doi.org/10.1016/j.jad. 2018.12.132

Nekić, M., \& Mamić, S. (2019). Intolerance of uncertainty and mindfulness as determinants of anxiety and depression in female students. Behavioral Sciences, 9(12), 135. https://doi.org/10.3390/ bs9120135

O’Bryan, E. M., Luberto, C. M., Kraemer, K. M., \& McLeish, A. C. (2018). An examination of mindfulness skills in terms of affect tolerance among individuals with elevated levels of health anxiety. Anxiety, Stress, \& Coping, 31(6), 702-713. https://doi.org/10. 1080/10615806.2018.1521515

O'Connor, T. G., Heron, J., \& Glover, V. (2002). Antenatal anxiety predicts child behavioral/emotional problems independently of postnatal depression. Journal of the American Academy of Child \& Adolescent Psychiatry, 41(12), 1470-1477. https://doi.org/10. 1097/00004583-200212000-00019

O'Hara, M. W. (1995). Postpartum depression: Causes and consequences. Springer-Verlag.

Ouellet, C., Langlois, F., Provencher, M. D., \& Gosselin, P. (2019). Intolerance of uncertainty and difficulties in emotion regulation: Proposal for an integrative model of generalized anxiety disorder. European Review of Applied Psychology, 69(1), 9-18. https://doi. org/10.1016/j.erap.2019.01.001

Papenfuss, I., Lommen, M. J. J., Grillon, C., Balderston, N. L., \& Ostafin, B. D. (2021). Responding to uncertain threat: A potential mediator for the effect of mindfulness on anxiety. Journal of Anxiety Disorders, 77, 102332. https://doi.org/10.1016/j.janxdis. 2020.102332

Paulus, D. J., Talkovsky, A. M., Heggeness, L. F., \& Norton, P. J. (2015). Beyond negative affectivity: A hierarchical model of global and transdiagnostic vulnerabilities for emotional disorders. Cognitive Behaviour Therapy, 44(5), 389-405. https://doi.org/10. 1080/16506073.2015.1017529

Podsakoff, P. M., MacKenzie, S. B., Lee, J.-Y., \& Podsakoff, N. P. (2003). Common method biases in behavioral research: A critical review of the literature and recommended remedies. Journal of Applied Psychology, 88(5), 879-903. https://doi.org/10.1037/ 0021-9010.88.5.879

Prime, H., Wade, M., \& Browne, D. T. (2020). Risk and resilience in family well-being during the COVID-19 pandemic. American Psychologist, 75(5), 631-643. https://doi.org/10.1037/amp00 00660

Rettie, H., \& Daniels, J. (2020). Coping and tolerance of uncertainty: Predictors and mediators of mental health during the COVID-19 pandemic. American Psychologist. https://doi.org/10.1037/amp00 00710

Schimmenti, A., Billieux, J., \& Starcevic, V. (2020). The four horsemen of fear: An integrated model of understanding fear experiences during the COVID-19 pandemic. Clinical Neuropsychiatry, 17(2), 41-45. https://doi.org/10.36131/CN20200202
Shaddix, C. (2014). An interpretative phenomenological study of the experience of parents who attended a mindfulness-based childbirth and parenting program [Unpublished doctoral dissertation]. The Wright Institute.

Siegel, D. J., \& Hartzell, M. (2003). Parenting from the inside out: How a deeper self-understanding can help you raise children who thrive. Penguin.

Sorenson, D. (1990). Uncertainty in pregnancy. Naacog's Clinical Issues in Perinatal and Women's Health Nursing, 1(3), 289-296.

Spijkerman, M. P. J., Pots, W. T. M., \& Bohlmeijer, E. T. (2016). Effectiveness of online mindfulness-based interventions in improving mental health: A review and meta-analysis of randomised controlled trials. Clinical Psychology Review, 45, 102-114. https:// doi.org/10.1016/j.cpr.2016.03.009

Treleaven, C. (2020). Intolerance of Uncertainty and Emotion Regulation in Pregnant Women. [Doctoral dissertation, University of Exeter]. Open Research Exeter. https://ore.exeter.ac.uk/repository/bitstream/handle/ 10871/123891/TreleavenC.pdf?sequence=2\&isAllowed=y

Tull, M. T., Edmonds, K. A., Scamaldo, K. M., Richmond, J. R., Rose, J. P., \& Gratz, K. L. (2020). Psychological outcomes associated with stay-at-home orders and the perceived impact of COVID-19 on daily life. Psychiatry Research, 289, 113098. https://doi.org/ 10.1016/j.psychres.2020.113098

Van den Heuvel, M. I., Donkers, F. C. L., Winkler, I., Otte, R. A., \& Van den Bergh, B. R. H. (2015). Maternal mindfulness and anxiety during pregnancy affect infants' neural responses to sounds. Social Cognitive and Affective Neuroscience, 10(3), 453-460. https://doi.org/10.1093/scan/nsu075

Van den Heuvel, M. I., Johannes, M. A., Henrichs, J., \& Van den Bergh, B. R. H. (2015). Maternal mindfulness during pregnancy and infant socio-emotional development and temperament: The mediating role of maternal anxiety. Early Human Development, 91(2), 103-108. https://doi.org/10.1016/j.earlhumdev.2014.12.003

VanTieghem, M., Thomason, M., Graham, A., Sullivan, E., Vatalaro, T., Espinoza-Heredia, C., Lenniger, C., \& van den Heuvel, M. I. (2020, November 23). COVID-19 and Perinatal Experiences Study. Retrieved from osf.io/uqhev

Yook, K., Kim, K.-H., Suh, S. Y., \& Lee, K. S. (2010). Intolerance of uncertainty, worry, and rumination in major depressive disorder and generalized anxiety disorder. Journal of Anxiety Disorders, 24(6), 623-628. https://doi.org/10.1016/j.janxdis.2010.04.003

Zabora, J., Brintzenhofeszoc, K., Jacobsen, P., Curbow, B., Piantadosi, S., Hooker, C., Owens, A., \& Derogatis, L. (2001). A new psychosocial screening instrument for use with cancer patients. Psychosomatics, 42(3), 241-246. https://doi.org/10.1176/appi.psy.42.3.241

Zacher, H., \& Rudolph, C. W. (2021). Individual differences and changes in subjective wellbeing during the early stages of the COVID-19 pandemic. American Psychologist, 76(1), 50-62. https://doi.org/10.1037/amp0000702

Publisher's Note Springer Nature remains neutral with regard to jurisdictional claims in published maps and institutional affiliations. 